\title{
Role of Nodal signalling in testis development and initiation of testicular cancer
}

\author{
Katrine Harpelunde Poulsen ${ }^{1,2}$ and Anne Jørgensen ${ }^{1,2}$ \\ ${ }^{1}$ Department of Growth and Reproduction, Rigshospitalet, University of Copenhagen, Copenhagen, Denmark and \\ ${ }^{2}$ International Research and Research Training Centre in Endocrine Disruption of Male Reproduction and Child \\ Health (EDMaRC), Copenhagen, Denmark
}

Correspondence should be addressed to A Jørgensen; Email: aj@rh.regionh.dk

\begin{abstract}
Testicular development from the initially bipotential gonad is a tightly regulated process involving a complex signalling cascade to ensure proper sequential expression of signalling factors and secretion of steroid hormones. Initially, Sertoli cell specification facilitates differentiation of the steroidogenic fetal Leydig cells and establishment of the somatic niche, which is critical in supporting the germ cell population. Impairment of the somatic niche during fetal life may lead to development of male reproductive disorders, including arrest of gonocyte differentiation, which is considered the first step in the testicular cancer pathogenesis. In this review, we will outline the signalling pathways involved in fetal testis development focusing on the Nodal pathway, which has recently been implicated in several aspects of testicular differentiation in both mouse and human studies. Nodal signalling plays important roles in germ cell development, including regulation of pluripotency factor expression, proliferation and survival. Moreover, the Nodal pathway is involved in establishment of the somatic niche, including formation of seminiferous cords, steroidogenesis and Sertoli cell function. In our outline of fetal testis development, important differences between human and mouse models will be highlighted to emphasise that information obtained from mouse studies cannot always be directly translated to humans. Finally, the implications of dysregulated Nodal signalling in development of the testicular cancer precursor, germ cell neoplasia in situ, and testicular dysgenesis will be discussed - none of which arise in rodents, emphasising the importance of human models in the effort to increase our understanding of origin and early development of these disorders.

Reproduction (2019) 158 R67-R77
\end{abstract}

\section{Introduction}

Testicular differentiation involves a tightly regulated and complex signalling cascade that is currently not completely characterised, although progress is continuously made in our understanding of the specific roles of signalling factors involved. Recently, several studies have implicated Nodal (and Activin) signalling as important pathways in the signalling cascade directing fetal testis development, with distinct roles in the regulation of germ cell development as well as in the establishment and function of the somatic niche (Souquet et al. 2012, Spiller et al. 2012, Miles et al. 2013, Wu et al. 2013, Tian-Zhong et al. 2016, Jørgensen et al. 2018). Understanding the mechanisms by which these pathways are involved and interact is important as even small alterations in signalling at this sensitive time point may result in failure of normal testicular development and/or function, which is associated with a number of male reproductive disorders later in life. The regulation of germ cell survival, proliferation and differentiation required to ensure the establishment of a normal germ cell population depends upon a complex combination of signalling factors and the interaction between germ cells and the surrounding somatic cells that together form the microenvironment known as the somatic niche (reviewed in Rotgers et al. 2018). It is hypothesised that even slightly altered signalling between germ cells and the somatic niche during fetal development can impair differentiation of a subpopulation of gonocytes that instead persist in their undifferentiated state with continued expression of pluripotency factors (reviewed in Rajpert-De Meyts 2006, Rajpert-De Meyts et al. 2016). This is considered to be the first step in the development of the testicular cancer precursor, germ cell neoplasia in situ (GCNIS), which later in life develops into testicular germ cell tumours (TGCTs) (Rajpert-De Meyts 2006, Rajpert-De Meyts et al. 2016). Altered signalling or timing of the expression of key factors in the testicular differentiation pathway may also impair the establishment of the somatic niche, which involves specification of Sertoli, fetal Leydig and peritubular myoid cell lineages as well as organisation and growth of the testis, including formation of the seminiferous cords. The effects of subtle alterations in signalling pathways during testicular 
development is considered the basis of the testicular dysgenesis syndrome (TDS), which comprise disorders of male reproductive health that manifest either at birth (cryptorchidism, hypospadias) or in young adulthood (reduced sperm counts, testicular germ cell cancer, primary hypogonadism), with a common origin that is a consequence of impaired testicular differentiation and/or function during fetal life (Skakkebaek et al. 2001, 2016).

\section{Fetal testis development}

During embryonic development, bipotential gonads (genital ridges) arise from thickening and proliferation of the coelomic epithelium, overlying the ventral-medial surface of the mesonephros. In humans, they appear around gestational week (GW) 4 and in mice they emerge around 10 days post coitum (dpc) (Wilhelm et al. 2013). Around GW 5-6 in humans and $10.5 \mathrm{dpc}$ in mice, the genital ridges become colonised by primordial germ cells (PGCs), the precursor cells of spermatozoa and oocytes, which have migrated from the proximal epiblast via the hindgut to the genital ridges (Fujimoto et al. 1977, Molyneaux et al. 2001, Wilhelm et al. 2013).

The sex-specific development of the bipotential gonads into testes or ovaries is determined by the presence or absence of the $\mathrm{Y}$ chromosome, respectively. The $\mathrm{Y}$ chromosome gene sex-determining region of chromosome $Y(S R Y)$ initiates the signalling cascade that results in testicular development. Sry is transiently upregulated around $10.5 \mathrm{dpc}$ in mice and in humans the expression of $S R Y$ is initiated around GW 6 (Berta et al. 1990, Koopman et al. 1990, Sinclair et al. 1990, Hacker et al. 1995, Hanley et al. 2000). Expression of $S R Y$ induces upregulation of male-specific genes in the gonad, including SOX9 (Sry-box containing gene 9), which promotes differentiation of pre-Sertoli cells. Sox 9 expression triggers the expression of Fgf9 and Amh in Sertoli cells, which act to suppress female fate pathways and ensure regression of the female Müllerian ducts, respectively, thereby promoting male differentiation (reviewed in Rotgers et al. 2018). Upon arrival of PGCs in the developing gonads, the germ cells are termed gonocytes in $\mathrm{XY}$ individuals. As a result of the initiation and progression of the male signalling pathway, the gonocytes and Sertoli cells become enclosed within the forming seminiferous cords, dividing the gonads into two compartments - the seminiferous cords containing the Sertoli cells and germ cells, and the interstitial space consisting of fetal Leydig cells, progenitors of adult Leydig cells and peritubular myeloid cells (Wilhelm et al. 2013). In mice, the seminiferous cords become evident at $12.5 \mathrm{dpc}$ and in human testes they are distinguishable from around GW 8-9 (Brennan \& Capel 2004, Ostrer et al. 2007).

Germ cells within the fetal gonads are highly proliferating during first trimester in both sexes, but with a substantially higher number of germ cells present in fetal ovaries (approximately 250,000 in GW 9) compared to fetal testes (30,000 germ cells in GW 9) (Bendsen et al. 2003, 2006). Another important distinction between male and female germ cells around this developmental time-point is the initiation of the first meiotic division in a sub-population of oogonia within fetal ovaries, while in fetal testes, initiation of meiosis is actively prevented. In mice, female germ cells enter meiosis at $13.5 \mathrm{dpc}$, whereas in humans, meiosis is initiated in an asynchronous manner starting from around GW 10-11 (Gondos et al. 1986, Bullejos \& Koopman 2004, Stoop et al. 2005, Bendsen et al. 2006). Initiation of meiosis is mediated at least in part by actions of retinoic acid (RA), which promote upregulation of the pre-meiosis marker Stra8 (stimulated by retinoic acid 8). Expression of additional factors involved in meiosis are subsequently initiated, resulting in meiotic entry and first meiotic division (Gaemers et al. 1996, Koubova et al. 2006, Le Bouffant et al. 2010, Jørgensen et al. 2012, Griswold 2016). In contrast, the initiation of meiosis is inhibited in fetal testes until puberty and in mice the germ cells enter a quiescent state. The primary mechanism by which meiosis is inhibited in mouse testes involves the actions of Cyp26b1 (cytochrome P450, family 26, subfamily b, polypeptide 1), which is a RA-metabolising enzyme expressed by the Sertoli cells (Bowles et al. 2006, Koubova et al. 2006). Other factors, such as Fgf9, Nanos2, Dmrt1 and Nodal have also been implicated in preventing initiation of meiosis in male germ cells in mice (Suzuki \& Saga 2008, Bowles et al. 2010, Matson et al. 2010, Souquet et al. 2012, Wu et al. 2013). In human fetal testes, the mechanisms responsible for preventing meiosis are not completely understood (reviewed in Jørgensen \& Rajpert-De Meyts 2014). However, several studies have found that CYP26B1 is expressed in both human fetal ovaries and testes, suggesting that, in contrast to mice, this is not a malespecific meiosis inhibitor (Childs et al. 2011, Jørgensen et al. 2012, Frydman et al. 2017). Conversely, the roles of other meiosis-inhibiting factors e.g. NANOS2 and DMRT1 appear to be more conserved between mice and humans based on their sexually dimorphic expression patterns in human gonads (Childs et al. 2011, Jørgensen et al. 2012). Interestingly, a recent study suggested that in humans, male and female gonads share several meiosis-preventing pathways, which likely explains the simultaneous presence of pre- and post-meiotic germ cells in human fetal ovaries (Frydman et al. 2017).

In the human fetal testis, gonocytes can be recognised by their expression of pluripotency factors, including OCT4, NANOG, C-KIT and AP2 $\gamma$ (Gaskell et al. 2004, Hoei-Hansen et al. 2004, Rajpert-De Meyts et al. 2004, Pauls et al. 2006). These factors are gradually downregulated starting from around GW 14-16 with simultaneous upregulation of MAGE-A4 expression, thereby marking the transition to pre-spermatogonia. Pre-spermatogonia are in addition to the expression of 
MAGE-A4 characterised by their distinct morphology and localisation adjacent to the basement membrane. In human fetal testes, the transition from gonocytes to prespermatogonia constitutes an important differentiation step during testis development as failure of gonocyte differentiation is considered to be the first step in the malignant transformation of germ cells, resulting in the development of GCNIS and subsequently in TGCTs (Skakkebaek 1987, Rajpert-De Meyts et al. 2016).

\section{The Nodal signalling pathway}

There is increasing evidence to suggest that TGF $\beta$ signalling plays important roles during fetal testis development, in particular a number of recent studies have implicated the Nodal pathway in germ cell development and establishment of the somatic niche (Souquet et al. 2012, Spiller et al. 2012, Miles et al. 2013, Wu etal. 2013, Tian-Zhong et al. 2016). The Nodal signalling pathway is part of the TGF $\beta$ superfamily which is involved in the regulation of numerous cellular processes, including cell differentiation, proliferation and apoptosis (Schier 2009). The TGF $\beta$ superfamily is generally divided into two branches based on which downstream effectors are activated. The first branch includes bone morphogenic proteins (BMPs) and the second branch consists of cytokines, growth differentiation factors (GDFs), Nodal, Activins and Inhibins. Since Nodal and Activin signal through essentially the same receptor complexes, redundancy between these signalling pathways is expected. This receptor complex consists of two serine/ threonine receptors; the type I receptor (Alk4/7) and type
II receptor (ActRIIA/B). Nodal and Activin bind to the extracellular domains of the type II receptors, leading to a conformational change that allows its dimerisation with the type I receptor. Dimerisation of the receptors results in the activation via phosphorylation of their intracellular domains. This in turn leads to phosphorylation of the signalling transducer Smad2/3 that together with Smad4 forms a ternary complex and translocate to the nucleus. Here, the Smad complex activates transcription of target genes (reviewed in Schier 2009, Papanayotou \& Collignon 2014) (Fig. 1).

In addition to ActRIIA/B and Alk4/7, signal transduction by Nodal requires the presence of the co-receptor Cripto (also known as teratocarcinoma derived growth factor 1; Tdgf1) that associates with the type I receptor and Nodal. Signalling by Nodal results in transcriptional activation of the Nodal gene itself as well as the inhibitor of the Nodal pathway Lefty 1 and Lefty2. Lefty acts as an endogenous inhibitor of Nodal by either binding to the obligate co-receptor Cripto, thus preventing the assembly of the required receptor complex or by direct binding to Nodal itself (Cheng et al. 2004). As Nodal stimulates both its own expression and the expression of the inhibitor Lefty $1 / 2$, the direct positive and negative feedback act to fine-tune signalling through this pathway (Sakuma et al. 2002, Schier 2009).

\section{Role of Nodal signalling in fetal testis development}

The majority of knowledge about the involvement of Nodal/Activin signalling in fetal testis development is obtained from mouse studies (Souquet et al. 2012, Spiller

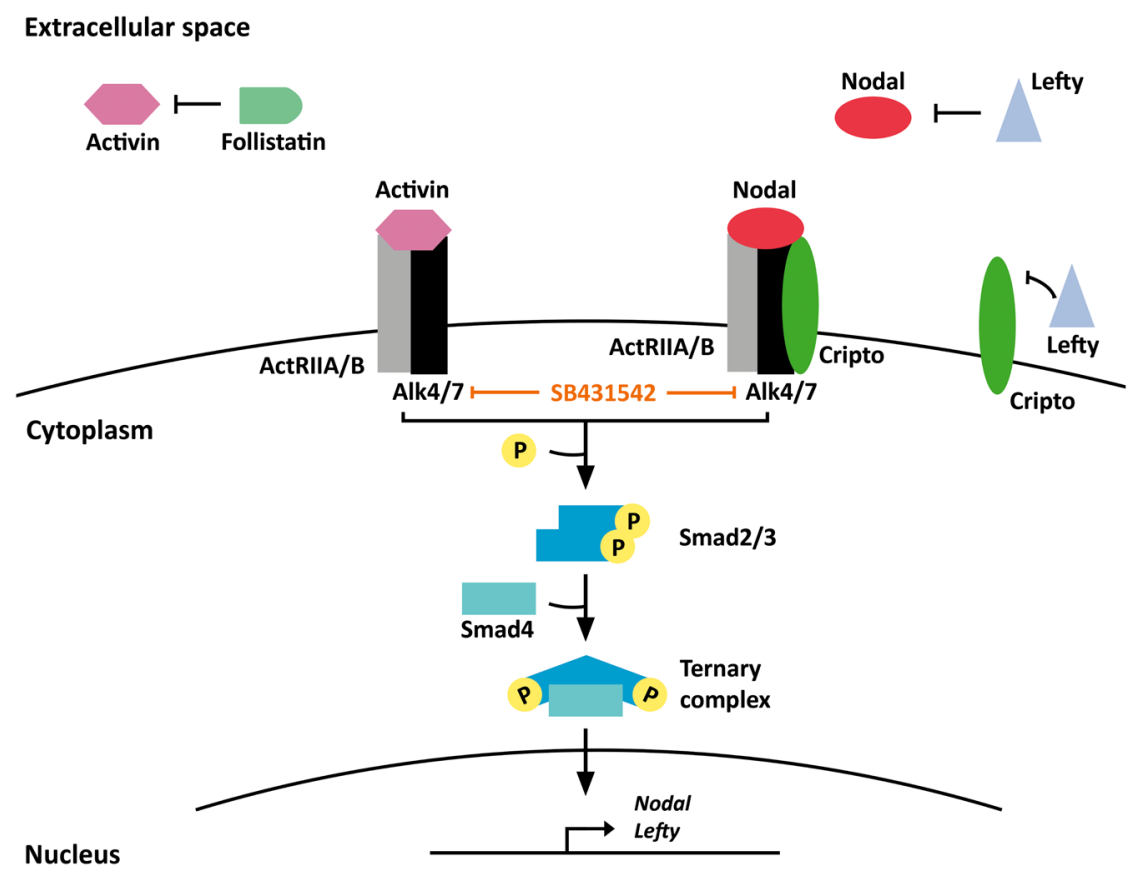

Figure 1 Overview of the Nodal and Activin signalling pathways. The two ligands, Activin and Nodal, mediate signals through a receptor complex consisting of Alk4/7 (type I receptor) and ActRIIA/B (type II receptor), with Nodal requiring the co-receptor Cripto. Upon binding of Nodal or Activin to the receptor complex, the receptors become activated by phosphorylation of their intracellular domains. This in turn leads to phosphorylation of the transcription factors Smad2/3, which then forms a ternary complex with Smad4. The complex translocates to the nucleus and acts to regulate gene transcription together with co-activators and co-repressors. Signalling by Nodal leads to transcription of Nodal itself and its endogenous inhibitor Lefty $1 / 2$. Lefty binds to either Nodal itself or the co-receptor Cripto to exert its inhibitory effect. Follistatin is the endogenous inhibitor of Activin signalling. The effect of the Alk4/5/7 inhibitor SB431542, which is used in several referenced studies, is indicated on the figure. SB431542 inhibits the activity of the Alk $4 / 7$ receptors, thereby preventing activation of Smad2/3 and thus signalling transduction by Nodal and Activin. 
et al. 2012, Miles et al. 2013, Wu et al. 2013, Tian-Zhong et al. 2016). However, we recently investigated the involvement of Nodal and Activin signalling in human fetal testes using a combination of ex vivo culture and xenografting approaches (Jørgensen et al. 2018). Below we will summarise and compare the currently available information regarding the role of Nodal signalling in mouse and human testicular development.

\section{Expression pattern of Nodal and Activin signalling factors in fetal testes}

In mouse fetal testes, Nodal signalling factors are predominantly expressed in the germ cells, including the co-receptor Cripto, Nodal itself and the endogenous inhibitors Lefty 1 and Lefty2 (Souquet et al. 2012, Spiller et al. 2012, Miles et al. 2013, Wu et al. 2013). Consistently, the receptors, Alk4/7 and Acvr2a/b (encoding ActRIIA/B), are expressed in male germ cells, indicating a role for this signalling pathway during mouse testis development. In contrast, Activin signalling factors appear to be the primary pathway in somatic cells (OCT4-negative cell population) in fetal mouse testes based on the expression of Inhba, Inhbb, Alk4/7 and Acvr2a/b (Souquet et al. 2012, Spiller et al. 2012, Miles et al. 2013, Wu et al. 2013). Moreover, active Nodal/Activin signalling has been demonstrated by the presence of phosphorylated SMAD2 in both male germ cells and somatic cells at 12.5-14.5 dpc (Spiller et al. 2012, Wu et al. 2013). In accordance, ALK4, ALK5, $A C R V 2 B, N O D A L, C R I P T O, L E F T Y, I N H B A$ and INHBB are expressed in the first and second trimester human fetal testis samples (Jørgensen et al. 2018), with NODAL expression found primarily in the germ cells ( $\mathrm{Li}$ et al. 2017). Thus, Nodal and Activin signalling also appear to be involved in human fetal testis development.

Nodal/Activin signalling has been shown to act downstream of the Fgf9 pathway, which plays an important role in the early reinforcement of male fate by promoting Sertoli cell differentiation and antagonising female fate through inhibition of Wnt4 expression (Jameson et al. 2012). It has been suggested that FGF9 expression precedes and triggers the expression of Cripto (Spiller et al. 2012, Wu et al. 2013), which subsequently initiate expression of Nodal and the endogenous inhibitors Lefty 1 and Lefty 2 as a response to the increased Cripto expression. The onset of Cripto expression has been reported to be $12.5 \mathrm{dpc}$ followed by Nodal, Lefty 1 and Lefty2 at 13.5 dpc (Spiller et al. 2012). Similarly, Nodal expression was shown to be highest from 12.5 to $13.5 \mathrm{dpc}$, with a subsequent decline in the expression at 13.5-15.5 dpc (Miles et al. 2013). In contrast, Souquet et al. found a peak in expression of all three Nodal pathway genes at $11.5 \mathrm{dpc}$ (Souquet et al. 2012). Despite these minor discrepancies, the studies have all described a transient expression pattern of the Nodal signalling factors during the critical developmental window of sex differentiation in mice. In human fetal testes, a similar transient expression pattern was not observed, as expression of NODAL, CRIPTO, LEFTY1 and LEFTY2 was found throughout the first and second trimester (Jørgensen et al. 2018). This difference highlights that the process of germ cell differentiation in mice takes place in a synchronous manner at 12.5$13.5 \mathrm{dpc}$, while gonocyte differentiation in humans is an asynchronous process spanning a much longer period of time starting from around GW 14-16 and continues throughout fetal life (Mitchell et al. 2008).

\section{Role of Nodal and Activin signalling in male fetal germ cells}

Several studies have examined the role of Nodal and Activin during mouse testis development by utilising either pharmaceutical inhibition of the pathways or gene-knockdown approaches (Souquet et al. 2012, Spiller et al. 2012, Miles et al. 2013, Wu et al. 2013, Tian-Zhong et al. 2016). Similarly, in the study using human fetal testes, pharmaceutical inhibition of Nodal and Activin signalling was used (Jørgensen et al. 2018). Simultaneous inhibition of Nodal and Activin signalling with SB431542 (ALK4/5/7 inhibitor) (Inman 2002) in ex vivo cultures of the first trimester human fetal testes resulted in almost complete loss of the gonocyte population. The observed effect of the inhibitor treatment was due to a combination of reduced proliferation and increased apoptosis and not a consequence of premature gonocyte differentiation. In line with the results from the first trimester testes, the number of both gonocytes and pre-spermatogonia was significantly reduced in the second trimester samples after simultaneous inhibition of Nodal and Activin signalling. Since treatment with SB431542 not only inhibits Nodal signalling, the effects of Nodal and Activin signalling were separated by treatments with recombinant Nodal, Lefty, Activin A and Follistatin, respectively, in ex vivo cultures of the first trimester fetal testes (Jørgensen et al. 2018). Treatment with the endogenous Nodal pathway inhibitor Lefty resulted in a lower number of OCT4 ${ }^{+}$ gonocytes, while stimulation with Nodal significantly increased the number of OCT4 ${ }^{+}$gonocytes, indicating that the Nodal pathway is directly involved in the regulation of pluripotency factor expression in human fetal gonocytes (Jørgensen et al. 2018). Interestingly, when Nodal signalling was initially stimulated in ex vivo cultures of the second trimester fetal testes followed by subsequent xenografting, an increase in the ratio of $\mathrm{OCT}_{4}{ }^{+}$gonocytes to the total number of germ cells was reported, suggesting prolonged expression of OCT4 in the gonocytes. This directly implicates Nodal signalling in the regulation of the gonocyte to pre-spermatogonia transition in human fetal testes (Jørgensen et al. 2018). In mouse fetal testes, Nodal signalling has also been shown to regulate the expression of pluripotency factors 
(Spiller et al. 2012, Miles et al. 2013, Tian-Zhong et al. 2016). In a hypomorphic Nodal mouse model, the expression of pluripotency factors (Nanog, Oct4 and Sox2) were downregulated, while markers of male germ cell differentiation were upregulated (Nanos2, p15 and Dnmt3l), indicating that Nodal functions to maintain pluripotency and delay differentiation in male germ cells (Spiller et al. 2012). In line with these findings, an independent study reported high expression of Fgf9 and Nodal signalling factors as well as persistence of Oct $4^{+} / \mathrm{Nanog}^{+}$gonocytes and prevention of germ cell differentiation in a conditional Emx2-knockdown mouse model (Tian-Zhong et al. 2016). Simultaneous inhibition of Fgf9 and Nodal signalling using SU5402 (FGFR tyrosine kinase inhibitor) (Mohammadi et al. 1997) and SB431542, respectively, reversed the pattern of pluripotency factor expression and differentiation in testes from $E m \times 2-k n o c k d o w n$ mice, indicating that EMX2 plays a role in male germ cell differentiation through regulation of Fgf9 and Nodal signalling. Moreover, reduced expression of Nanog was found in mouse testes cultured with SB431542, supporting the notion that Nodal signalling is involved in maintaining the expression of pluripotency factors in male germ cells (Miles et al. 2013). The finding that Nodal signalling is involved in the regulation of pluripotency factor expression in fetal male germ cells is in accordance with previous findings in mouse epiblast stem cells and human embryonic stem cells, where Nodal/Activin signalling has been shown to maintain the expression of pluripotency factors (Vallier et al. 2004, Camus et al. 2006).

In human fetal testes, both simultaneous inhibition of Nodal and Activin signalling and inhibition of the two pathways separately reduced the number of germ cells, suggesting overlapping functions of Nodal and Activin signalling in germ cell survival (Jørgensen et al. 2018). Correspondingly, Nodal and Activin signalling have also been suggested to be involved in germ cell survival in mouse fetal testes (Wu et al. 2013). To gain insight into the long-term consequences of reduced Nodal and Activin signalling, human fetal testis tissue initially treated with SB431542 in ex vivo culture was xenografted into nude mice (without additional treatment) (Jørgensen et al. 2018). The xenografting period did not rescue the effects on the germ cell population in either the first or second trimester testis samples, consistent with an initial loss of the germ cells upon ex vivo exposure to SB431542. Accordingly, stimulation of Nodal signalling in ex vivo cultures of the first trimester fetal testes increased the number of $\mathrm{OCT} 4^{+}$gonocytes.

In mouse fetal testes, Nodal/Activin signalling has been implicated in preventing premature meiotic entry of germ cells (Souquet et al. 2012, Wu et al. 2013). In the study by Souquet and colleagues, treatment with
SB431542 in ex vivo cultures of mouse fetal testes resulted in upregulation of the meiosis markers $\gamma \mathrm{H} 2 \mathrm{AX}, \mathrm{SYCP} 3$ and Dmc1 (Souquet et al. 2012). Conversely, in cultured mouse fetal ovaries stimulated with recombinant Nodal, expression of the pre-meiosis marker Stra8 decreased, thus suggesting that a reduced number of germ cells initiated meiosis. In accordance, an independent study found increased expression of the meiosis markers Stra8, Dmc1 and Rec8 following SB431542 treatment in ex vivo cultures of mouse fetal testes (Wu et al. 2013), while the study by Spiller and colleagues did not detect increased expression of Stra8 in their Nodalknockdown model (Spiller et al. 2012). However, in this model the expression of Nodal was only reduced to approximately $30 \%$ of wild-type Nodal expression, and therefore, it is possible that the remaining expression of Nodal maintained the inhibition of premature initiation of meiosis and promotion of male fate. In human fetal testes, inhibition of Nodal and Activin signalling with SB431542 did not result in the initiation of meiosis as judged by immunohistochemical analysis of SCP3 expression, but since the majority of germ cells were lost this was difficult to evaluate (Jørgensen et al. 2018).

The Nodal/Activin signalling pathway has also been implicated in promoting male differentiation, including mitotic arrest of germ cells in mouse fetal testes (Souquet et al. 2012, Miles et al. 2013, Wu etal. 2013). The reduced expression of Nodal upon SB431542 treatment in mouse testes also resulted in decreased expression of male germ cell differentiation markers Nanos2 and Dnmt3l (Souquet et al. 2012, Wu et al. 2013). Reduced Nanos2 expression was confirmed at $14.5 \mathrm{dpc}$ in the conditional Nodal-knockout mouse model, but the expression of Nanos 2 was normal at $16.5 \mathrm{dpc}$, indicating that this was a transient effect (Wu et al. 2013). In the same model, expression levels of Lefty $1 / 2$ and phosphorylated SMAD2 were unaffected, despite the fact that Nodal expression was demonstrated to be successfully abolished, indicating that compensatory signalling by, for example, Activin might be involved (Wu et al. 2013). In an independent study, it was reported that treatment with SB431542 reduced the expression of the malespecific marker DPPA4 in a subset of male germ cells (Miles et al. 2013). The reduced DPPA4 expression was accompanied by an increased expression of the mitosis marker KI-67, consistent with increased mitotic activity of germ cells isolated from SB431542-treated testes. Accordingly, in ex vivo cultures of mouse fetal testes treated with SB431542, increased expression of mitosis markers was observed, suggesting a role for Nodal/ Activin signalling in the regulation of mitotic arrest of male germ cells. In contrast, Spiller et al. reported increased expression of male germ cell differentiation markers Nanos2, p15 and Dnmt3/ in their hypomorphic Nodal mouse model (Spiller et al. 2012). 


\section{Effects of Nodal and Activin signalling on the testicular somatic niche}

In addition to the effects on germ cells, Nodal and Activin signalling were also reported to affect somatic cell function in human fetal testes (Jørgensen et al. 2018). Especially, the Nodal pathway was shown to play an important role in the establishment of the seminiferous cords. Treatment with both SB431542 and recombinant Lefty in ex vivo cultures of the first trimester samples resulted in the disruption of the seminiferous cord formation. However, no effects on seminiferous cords were observed after SB431542 treatment in the second trimester fetal testes, suggesting that Nodal (and Activin) signalling is not involved in the maintenance of seminiferous cords. Interestingly, the seminiferous cord structure was re-established in SB431542-treated first trimester testis samples after xenografting, indicating that the initial disruptive effects of simultaneous inhibition of Nodal and Activin signalling can be rescued with time. In mice, two independent studies have also implicated Nodal/Activin signalling in the formation of seminiferous cords (Miles et al. 2013, Wu et al. 2013). The simultaneous inhibition of Nodal and Activin signalling in the first trimester human fetal testes did not affect the expression of the Sertoli cell marker SOX9 nor did it induce trans-differentiation of the Sertoli cells into granulosa like-cells (FOXL2 ${ }^{+}$) despite disruption of the seminiferous cords (Jørgensen et al. 2018), consistent with results from mice (Souquet et al. 2012, Miles et al. 2013). This is to some extent in line with an independent study that did not find altered Wnt4 or Fox/2 expression upon SB431542 treatment of mouse fetal testes, although increased expression of Bmp2 and Follistatin (considered possible targets of WNT4 and FOXL2) were observed, leading the authors to suggest that Nodal/ Activin signalling may suppress female reprogramming of the Sertoli cells (Wu et al. 2013). Despite the continued expression of SOX9 in ex vivo cultures of the first trimester fetal testes exposed to SB431542, expression of COUP-TFII (marker of interstitial cells) and $\mathrm{AMH}$ (Sertoli cell marker) as well as secretion of AMH were reduced, suggesting additional effects on the function of the somatic niche (Jørgensen et al. 2018). Subsequent xenografting of the SB431542-treated first trimester fetal testes appeared to restore normal expression of COUPTFII and AMH. Specific inhibition of the Nodal signalling pathway following treatment with recombinant Lefty in ex vivo cultures of first trimester fetal testes appeared to decrease the expression of $\mathrm{AMH}$, but with no significant effect on AMH secretion (Jørgensen et al. 2018). In contrast, Nodal stimulation increased AMH secretion, while no apparent effect on the expression of COUPTFIl was observed after manipulating signalling by Nodal in either direction. Manipulation with the Activin signalling pathway did not alter expression or secretion of $\mathrm{AMH}$. In mice, effects on Sertoli cells have also been reported following SB431542 treatment in fetal testis cultures, including impaired arrangement of the Sertoli cells and a reduced proliferative capacity (Miles et al. 2013). Since the interaction between the somatic niche and germ cells is crucial for normal germ cell development, it is likely that some of the effects on germ cell observed after SB431542 and Lefty treatments are mediated via alterations to the somatic niche rather than being a direct effect of Nodal inhibition (Fig. 2).

The study in human fetal testes was the first to report reduced androgen production (testosterone and androstenedione) following simultaneous inhibition of Nodal and Activin signalling in ex vivo cultures of the first trimester samples (Jørgensen et al. 2018). Since the levels of steroidogenic precursors 17-hydroxyprogesterone (17$\mathrm{OHP}$ ) and progesterone were also elevated, this could indicate reduced CYP17A1 enzyme activity. The effect on androgen production was not completely rescued following xenografting as evidenced by significantly reduced host mouse seminal vesicle weight (readout of testosterone production by tissue grafts in castrated male mice) and serum testosterone levels (Jørgensen et al. 2018). Interestingly, stimulation of the Nodal pathway in ex vivo cultures of the first trimester samples affected the androgen production in the opposite direction, with increased levels of androstenedione and dehydroepiandrosterone (DHEAS) reported, while levels of the early precursors 17-OHP and cortisone were reduced (Jørgensen et al. 2018).

\section{Involvement of dysregulated Nodal signalling in reproductive disorders?}

Increasing the understanding of underlying mechanisms directing fetal testis development are important also in the context of the fetal origin of male reproductive disorders comprised within TDS. Since continued expression of pluripotency factors and failure of a sub-population of gonocytes to differentiate to prespermatogonia during fetal testis development are considered the key initial step in the testicular cancer pathogenesis, the recent finding of the Nodal pathway as a regulator of pluripotency factor expression in fetal male germ cells (Spiller et al. 2012, Miles et al. 2013, Tian-Zhong et al. 2016, Jørgensen et al. 2018) has important implications for the understanding of malignant transformation of germ cells. Importantly though, the regulation of pluripotency factor expression and transition from gonocyte to pre-spermatogonia are not well characterised, but are understood to constitute a multifactorial and polygenic process in which Nodal signalling is one among several pathways involved. However, the increased number of gonocytes and prolonged expression of pluripotency factors observed after stimulation of the Nodal pathway (Jørgensen et al. 2018) provides insight into a possible mechanism by 


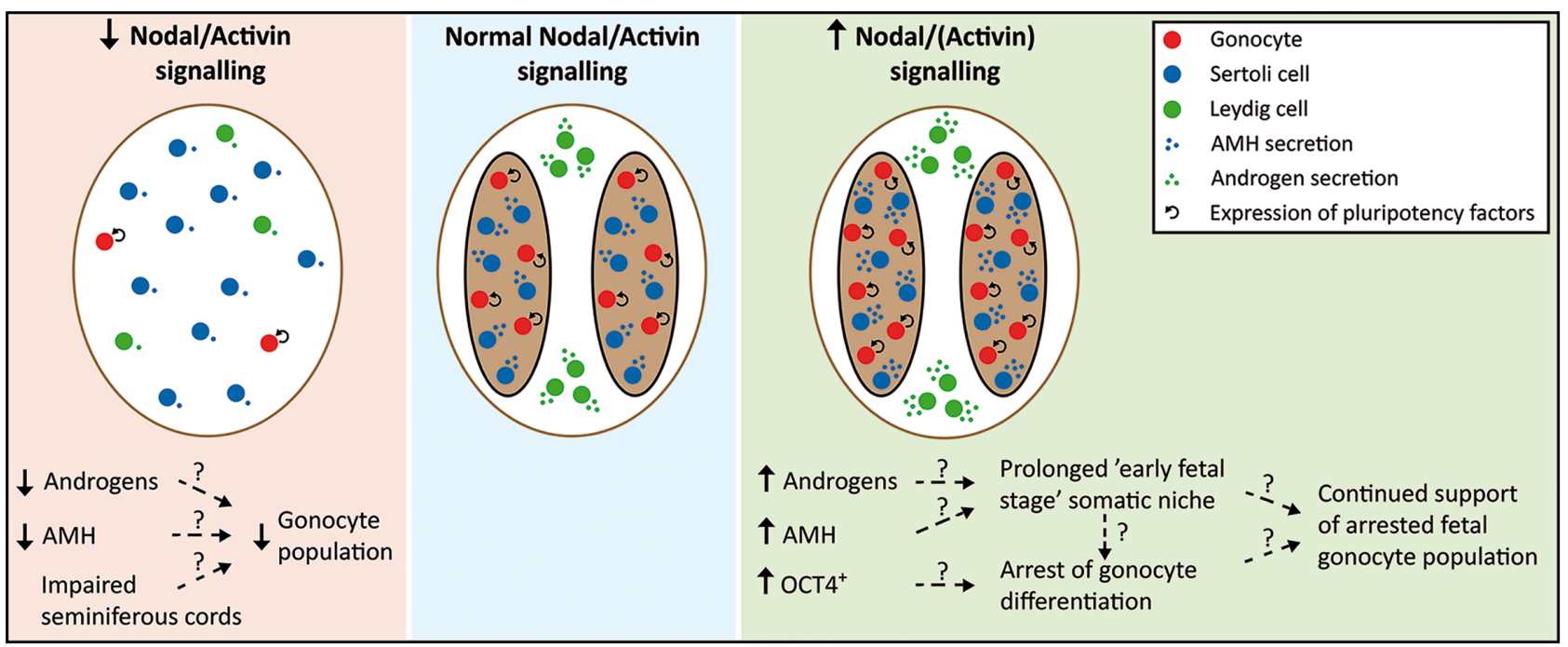

Figure 2 Summary of effects following manipulation of Nodal/Activin signalling in human fetal testes. The middle part of the figure (blue area) illustrates Nodal/Activin signalling in normal human fetal testes with formation of seminiferous cords, AMH secretion in Sertoli cells and steroidogenesis (including androgen production) in the fetal Leydig cells. Together, the somatic niche supports the survival and proliferation of $\mathrm{OCT}_{4}+$ gonocytes. The left part of the figure (red area) illustrates the situation where Nodal and Activin signalling have been simultaneously inhibited resulting in impaired formation of seminiferous cords, reduced expression and secretion of AMH as well as reduced production of androgens. This impaired somatic niche fails to sufficiently support the gonocyte population $\left(\mathrm{OCT} 4^{+}\right)$, which are most likely lost as consequence. The right part of the figure (green area) illustrates the situation where the Nodal pathway is stimulated (and Activin signalling is normal) resulting in increased $\mathrm{AMH}$ and androgen secretion in addition to an increased number of $\mathrm{OCT}_{4}^{+}$gonocytes. The effect on pluripotency factor expression in the gonocytes is most likely direct, but the prolonged 'early fetal stage' of the somatic niche probably contributes to their impaired differentiation to pre-spermatogonia, and the continued support of the arrested gonocytes.

which pluripotency factor expression can be maintained if this pathway is dysregulated (Fig. 3).

In line with the multifactorial process of testicular development and regulation of pluripotency factor expression in germ cells, it is known that the risk of developing GCNIS and subsequently TGCTs is increased in some patients with Differences of Sex Development (also known as Disorders of Sex Development, DSD), which covers a wide range of medical diagnoses related to atypical gonadal development due to a genetic defect. The high risk of germ cell malignancy is mainly related to DSD patients with defects in genes involved in the signalling cascade directing testis development, demonstrating that disruption of this tightly controlled process also affects germ cell differentiation. Moreover, development of GCNIS and TGCTs is included in TDS in which genetic susceptibility as well as lifestyle and environmental factors are considered to impact the risk of developing the male reproductive disorders included in the syndrome (Skakkebaek et al. 2001, 2016). Interestingly, despite the different aetiologies of DSD and TDS, the pathogenesis of GCNIS and TGCTs appears to be similar with failure of gonocyte differentiation and continuous expression of pluripotency factors as the initial steps (reviewed in Jørgensen et al. 2015).

Another important determinant of the risk for developing germ cell malignancies in DSD patients is the androgen responsiveness of the gonads, with a high risk in DSD patients with partial androgen insensitivity syndrome (Jørgensen et al. 2015). This is in line with the understanding that timing and level of androgen production are important for masculinisation of the foetus, including correct male-specific differentiation of the fetal gonads (Sharpe 2006). Reduced androgen production and/or action from the fetal testis is included in TDS, and it has been suggested that reduced androgen secretion during fetal development (in rats during the specific time of the masculinisation programming window; Welsh et al. 2008) alters signalling between the germ cells and their somatic niche, resulting in arrested gonocyte differentiation and prolonged expression of pluripotency factors in these cells (Rajpert-De Meyts 2006, Rajpert-De Meyts et al. 2016). The observed reduction in androgen secretion in human fetal testes following simultaneous inhibition of the Nodal and Activin pathway with only partial rescue of the effect (Jørgensen et al. 2018), could suggest long-term effects on androgen production. This is in line with a previous study in rodents, where it was demonstrated that progenitor stem cells for adult Leydig cells were present in the fetal testis and that the number of these were severely reduced when the androgen production in the fetal testis was reduced (Kilcoyne et al. 2014).

Focal testicular dysgenesis is another important feature of both DSD and TDS, which is frequently observed in testicular biopsies from these patients (Skakkebaek et al. 2001, Hoei-Hansen et al. 2003). 


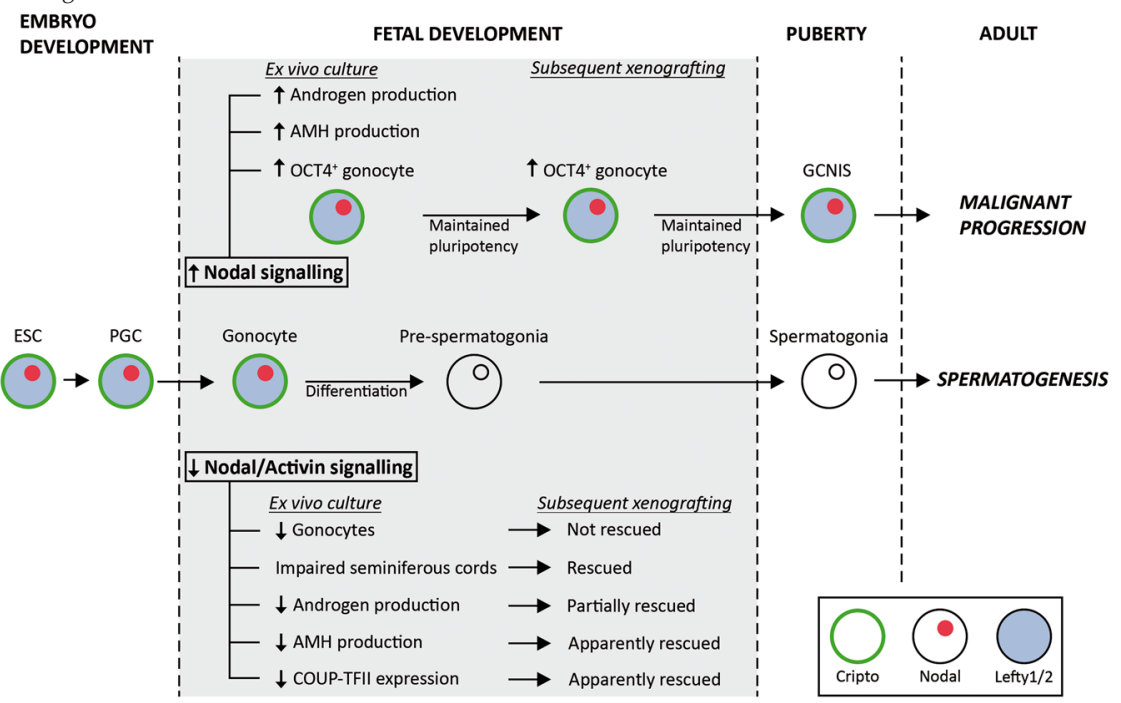

Figure 3 Summary of effects following manipulation of the Nodal signalling pathway in human fetal testis development (grey area) and its implications for the development of the testicular cancer precursor, germ cell neoplasia in situ (GCNIS). Nodal signalling factors are expressed in human fetal gonocytes (indicated by colour code). In the central part of the figure normal testis development is illustrated, in which gonocytes undergo differentiation to pre-spermatogonia during fetal development and spermatogenesis is initiated after puberty. Stimulation of Nodal signalling (top part of figure) results in an increased number of OCT4 ${ }^{+}$gonocytes as well as increased production of $\mathrm{AMH}$ and androgen precursors in ex vivo cultures of human fetal testes. Subsequent xenografting maintains OCT4 expression in a sub-population of gonocytes, implicating Nodal signalling in the regulation of pluripotency factor expression and thereby in the development of GCNIS and subsequent malignant progression. Diminished Nodal signalling (bottom part of figure) results in loss of gonocytes, impaired seminiferous cord structure, reduced $\mathrm{AMH}$ and androgen production and lower expression of COUP-TFII in ex vivo cultures of human fetal testes. Subsequent xenografting into castrated nude mice to determine long-term effects of short-term inhibition of Nodal signalling, do not rescue the gonocyte population, but the effects on seminiferous cord structure and partially the androgen production is rescued with time in addition to the apparent rescue of AMH production and COUP-TFIl expression. ESC, embryonal stem cell; GCNIS, germ cell neoplasia in situ; PGC, primordial germ cell.

This includes morphological alterations like abnormalshaped seminiferous tubules, Leydig cell nodules and Sertoli-cell-only tubules in which the Sertoli cells are occasionally undifferentiated. The induced testicular dysgenesis observed after simultaneous inhibition of Nodal and Activin signalling in both human and mouse fetal testes (Miles et al. 2013, Wu et al. 2013, Jørgensen et al. 2018), could suggest that dysregulated Nodal and/ or Activin signalling may be one of multiple signalling pathways involved when testicular dysgenesis develops. However, there is an important difference between the testicular phenotype observed in biopsies from patients, which is focal, and the complete dysgenesis observed in the fetal testes following inhibition of Nodal (and Activin) signalling, making direct comparison difficult. The simultaneous inhibition of Nodal/Activin signalling in human fetal testes, resulted in an almost complete loss of the gonocyte population (Jørgensen et al. 2018) rather than arrest of the gonocyte to pre-spermatogonia transition as may have been expected. This could be a consequence of the 'complete' testicular dysgenesis observed in these fetal testes (Fig. 2). In line with this notion, previous studies in which specific signalling pathways were manipulated resulting in testicular dysgenesis also substantially reduced the number of gonocytes without arrest of gonocyte differentiation being observed (Wu et al. 2013, Jørgensen et al. 2015).
Interestingly, a recent study in which DMRT1 expression was repressed in human fetal testes using a gene-editing approach, focal testicular dysgenesis was observed as well as increased expression of OCT4 (Macdonald et al. 2018). However, germ cells (especially gonocytes) were rarely observed in areas with focal testicular dysgenesis (Macdonald et al. 2018), indicating that these cells were lost most likely due to insufficient support from the somatic niche. These observations emphasise that it would be highly relevant to further examine the effects on gonocyte to pre-spermatogonia transition in a fetal testis model with focal testicular dysgenesis to better address this in future studies. Despite these limitations and the need for a cautious interpretation of the results, the finding that Nodal signalling is involved in the regulation of pluripotency factor expression (Spiller et al. 2012, Miles et al. 2013, Tian-Zhong et al. 2016, Jørgensen et al. 2018) and in particular the prolonged expression of pluripotency factors following stimulation of Nodal signalling (Jørgensen et al. 2018), highlight the importance of this pathway in normal testis development and germ cell differentiation. Importantly though, the signalling cascade ensuring normal fetal testis development is complex and dysregulation of any of the pathways involved may result in alterations consistent with impaired germ cell development, reduced androgen secretion and testicular dysgenesis 
suggested to be involved in the initial development of germ cell malignancy.

The novel insight into the involvement of Nodal signalling in testis development obtained during recent years and the implications for a role in the development of GCNIS and subsequent TGCTs when the pathway is dysregulated should be addressed in future studies. There are already studies demonstrating that Nodal signalling factors are overexpressed in human samples containing GCNIS and TGCTs, supporting the notion that this pathway may also play a role in the continued malignant transformation of germ cells (Baldassarre et al. 1997, Spiller et al. 2012, Nettersheim et al. 2015). Summarising the current knowledge about Nodal signalling in the progression of germ cell malignancy is beyond the scope of this review and have been reviewed elsewhere (Spiller et al. 2013, 2017). Future studies examining in more detail the effects of manipulating Nodal signalling on fetal testis development, particularly on germ cell differentiation - possibly using gene editing approaches in fetal testis cultures - may provide important insight into the role of the Nodal pathway in the pathogenesis of testicular germ cell cancer and delineate important information relevant for the understanding of male reproductive disorders.

\section{Declaration of interest}

The authors declare that there is no conflict of interest that could be perceived as prejudicing the impartiality of this review.

\section{Funding}

This work was supported in part by an ESPE Research Fellowship, sponsored by Novo Nordisk A/S to A Jørgensen. Additional funding for this work was obtained from The Danish Cancer Society (Grant no: R72-A4335-13-S2, A Jørgensen), The Erichssen Family Fund, Dagmar Marshalls Fund and Aase \& Ejnar Danielsens Fund.

\section{Acknowledgements}

The authors wish to thank Dr Ewa Rajpert-De Meyts for insightful comments and careful revision of the manuscript.

\section{References}

Baldassarre G, Romano A, Armenante F, Rambaldi M, Paoletti I, Sandomenico C, Pepe S, Staibano S, Salvatore G, De Rosa G et al. 1997 Expression of teratocarcinoma-derived growth factor-1 (TDGF-1) in testis germ cell tumors and its effects on growth and differentiation of embryonal carcinoma cell line NTERA2/D1. Oncogene 15 927-936. (https://doi.org/10.1038/sj.onc.1201260)

Bendsen E, Byskov AG, Laursen SB, Larsen HPE, Andersen CY \& Westergaard LG 2003 Number of germ cells and somatic cells in human fetal testes during the first weeks after sex differentiation. Human Reproduction 18 13-18. (https://doi.org/10.1093/humrep/deg057)
Bendsen E, Byskov AG, Andersen CY \& Westergaard LG 2006 Number of germ cells and somatic cells in human fetal ovaries during the first weeks after sex differentiation. Human Reproduction 21 30-35. (https:// doi.org/10.1093/humrep/dei280)

Berta P, Hawkins JR, Sinclair AH, Taylor A, Griffiths BL, Goodfellow PN \& Fellous M 1990 Genetic evidence equating SRY and the testis-determining factor. Nature 348 448-450. (https://doi.org/10.1038/348448A0)

Bowles J, Knight D, Smith C, Wilhelm D, Richman J, Mamiya S, Yashiro K, Chawengsaksophak K, Wilson MJ, Rossant J et al. 2006 Retinoid signaling determines germ cell fate in mice. Science 312 596-600. (https://doi.org/10.1126/science.1125691)

Bowles J, Feng CW, Spiller C, Davidson TL, Jackson A \& Koopman P 2010 FGF9 suppresses meiosis and promotes male germ cell fate in mice. Developmental Cell 19 440-449. (https://doi.org/10.1016/j. devcel.2010.08.010)

Brennan J \& Capel B 2004 One tissue, two fates: molecular genetic events that underlie testis versus ovary development. Nature Reviews: Genetics 5 509-521. (https://doi.org/10.1038/nrg1381)

Bullejos M \& Koopman P 2004 Germ cells enter meiosis in a rostro-caudal wave during development of the mouse ovary. Molecular Reproduction and Development 68 422-428. (https://doi.org/10.1002/mrd.20105)

Camus A, Perea-Gomez A, Moreau A \& Collignon J 2006 Absence of Nodal signaling promotes precocious neural differentiation in the mouse embryo. Developmental Biology 295 743-755. (https://doi. org/10.1016/j.ydbio.2006.03.047)

Cheng SK, Olale F, Brivanlou AH \& Schier AF 2004 Lefty blocks a subset of TGF $\beta$ signals by antagonizing EGF-CFC coreceptors. PLoS Biology 2 E30. (https://doi.org/10.1371/journal.pbio.0020030)

Childs AJ, Cowan G, Kinnell HL, Anderson RA \& Saunders PTK 2011 Retinoic acid signalling and the control of meiotic entry in the human fetal gonad. PLOS ONE 6 e20249. (https://doi.org/10.1371/journal. pone.0020249)

Frydman N, Poulain M, Arkoun B, Duquenne C, Tourpin S, Messiaen S, Habert R, Rouiller-Fabre V, Benachi A \& Livera G 2017 Human foetal ovary shares meiotic preventing factors with the developing testis. Human Reproduction 32 631-642. (https://doi.org/10.1093/humrep/ dew343)

Fujimoto T, Miyayama Y \& Fuyuta M 1977 The origin, migration and fine morphology of human primordial germ cells. Anatomical Record 188 315-330. (https://doi.org/10.1002/ar.1091880305)

Gaemers IC, van Pelt AM, van der Saag PT \& de Rooij DG 1996 Alltrans-4-oxo-retinoic acid: a potent inducer of in vivo proliferation of growth-arrested A spermatogonia in the vitamin A-deficient mouse testis. Endocrinology 137 479-485. (https://doi.org/10.1210/ endo.137.2.8593792)

Gaskell TL, Esnal A, Robinson LLL, Anderson RA \& Saunders PTK 2004 Immunohistochemical profiling of germ cells Within the human fetal testis: identification of three subpopulations. Biology of Reproduction 71 2012-2021. (https://doi.org/10.1095/biolreprod.104.028381)

Gondos B, Westergaard L \& Byskov AG 1986 Initiation of oogenesis in the human fetal ovary: ultrastructural and squash preparation study. American Journal of Obstetrics and Gynecology 155 189-195. (https:// doi.org/10.1016/0002-9378(86)90109-2)

Griswold MD 2016 Spermatogenesis: the commitment to meiosis. Physiological Reviews $96 \quad 1-17 . \quad$ (https://doi.org/10.1152/ physrev.00013.2015)

Hacker A, Capel B, Goodfellow P \& Lovellbadge R 1995 Expression of sry, the mouse sex-determining gene. Development 121 1603-1614.

Hanley NA, Hagan DM, Clement-Jones M, Ball SG, Strachan T, SalasCortés L, McElreavey K, Lindsay S, Robson S, Bullen P et al. 2000 SRY, SOX9, and DAX1 expression patterns during human sex determination and gonadal development. Mechanisms of Development 91 403-407. (https://doi.org/10.1016/S0925-4773(99)00307-X)

Hoei-Hansen CE, Holm M, Rajpert-De Meyts E \& Skakkebaek NE 2003 Histological evidence of testicular dysgenesis in contralateral biopsies from 218 patients with testicular germ cell cancer. Journal of Pathology 200 370-374. (https://doi.org/10.1002/path.1372)

Hoei-Hansen CE, Nielsen JE, Almstrup K, Sonne SB, Graem N, Skakkebaek NE, Leffers H \& Rajpert-De Meyts E 2004 Transcription factor AP-2gamma is a developmentally regulated marker of testicular carcinoma in situ and germ cell tumors. Clinical Cancer Research 10 8521-8530. (https://doi.org/10.1158/1078-0432.CCR-04-1285) 
Inman GJ, Nicolás FJ, Callahan JF, Harling JD, Gaster LM, Reith AD, Laping NJ \& Hill CS 2002 SB-431542 is a potent and specific inhibitor of transforming growth factor-beta superfamily type I activin receptor-like kinase (ALK) receptors ALK4, ALK5, and ALK7. Molecular Pharmacology 62 65-74. (https://doi.org/10.1124/mol.62.1.65)

Jameson SA, Lin YT \& Capel B 2012 Testis development requires the repression of Wnt4 by Fgf signaling. Developmental Biology 370 24-32. (https://doi.org/10.1016/j.ydbio.2012.06.009)

Jørgensen A, Lindhardt Johansen $M$, Juul A, Skakkebaek NE, Main KM \& Rajpert-De Meyts E 2015 Pathogenesis of germ cell neoplasia in testicular dysgenesis and disorders of sex development. Seminars in Cell and Developmental Biology 45 124-137. (https://doi.org/10.1016/j. semcdb.2015.09.013)

Jørgensen A, Macdonald J, Nielsen JE, Kilcoyne KR, Perlman S, Lundvall L, Langhoff Thuesen L, Juul Hare K, Frederiksen H, Andersson AM et al. 2018 Nodal signaling regulates germ cell development and establishment of seminiferous cords in the human fetal testis. Cell Reports 251924. e4-1937.e4. (https://doi.org/10.1016/j.celrep.2018.10.064)

Jørgensen A \& Rajpert-De Meyts E 2014 Regulation of meiotic entry and gonadal sex differentiation in the human: normal and disrupted signaling. Biomolecular Concepts 5 331-341. (https://doi.org/10.1515/ bmc-2014-0014)

Jørgensen A, Nielsen JE, Blomberg jensen M, Graem N \& Rajpert-De Meyts E 2012 Analysis of meiosis regulators in human gonads: a sexually dimorphic spatio-temporal expression pattern suggests involvement of DMRT1 in meiotic entry. Molecular Human Reproduction 18 523-534. (https://doi.org/10.1093/molehr/gas030)

Jørgensen A, Nielsen JE, Perlman S, Lundvall L, Mitchell RT, Juul A \& Rajpert-De Meyts E 2015 Ex vivo culture of human fetal gonads: manipulation of meiosis signalling by retinoic acid treatment disrupts testis development. Human Reproduction 30 2351-2363. (https://doi. org/10.1093/humrep/dev194)

Kilcoyne KR, Smith LB, Atanassova N, Macpherson S, McKinnell C, van den Driesche S, Jobling MS, Chambers TJG, De Gendt K, Verhoeven G et al. 2014 Fetal programming of adult Leydig cell function by androgenic effects on stem/progenitor cells. PNAS 111 E1924-E1932. (https://doi. org/10.1073/pnas.1320735111)

Koopman P, Münsterberg A, Capel B, Vivian N \& Lovell-Badge R 1990 Expression of a candidate sex-determining gene during mouse testis differentiation. Nature 348 450-452. (https://doi.org/10.1038/348450a0)

Koubova J, Menke DB, Zhou Q, Capel B, Griswold MD \& Page DC 2006 Retinoic acid regulates sex-specific timing of meiotic initiation in mice. PNAS 103 2474-2479. (https://doi.org/10.1073/pnas.0510813103)

Le Bouffant R, Guerquin MJ, Duquenne C, Frydman N, Coffigny H, Rouiller-Fabre V, Frydman R, Habert R \& Livera G 2010 Meiosis initiation in the human ovary requires intrinsic retinoic acid synthesis. Human Reproduction 25 2579-2590. (https://doi.org/10.1093/humrep/ deq195)

Li L, Dong J, Yan L, Yong J, Liu X, Hu Y, Fan X, Wu X, Guo H, Wang X et al. 2017 Single-cell RNA-seq analysis maps development of human germline cells and gonadal niche interactions. Cell Stem Cell 20858. e4-873.e4. (https://doi.org/10.1016/j.stem.2017.03.007)

Macdonald J, Kilcoyne KR, Sharpe RM, Kavanagh Á, Anderson RA, Brown P, Smith LB, Jørgensen A \& Mitchell RT 2018 DMRT1 repression using a novel approach to genetic manipulation induces testicular dysgenesis in human fetal gonads. Human Reproduction 33 2107-2121. (https://doi.org/10.1093/humrep/dey289)

Matson CK, Murphy MW, Griswold MD, Yoshida S, Bardwell VJ \& Zarkower D 2010 The mammalian doublesex homolog DMRT1 is a transcriptional gatekeeper that controls the mitosis versus meiosis decision in male germ cells. Developmental Cell 19 612-624. (https:// doi.org/10.1016/j.devcel.2010.09.010)

Miles DC, Wakeling SI, Stringer JM, van den Bergen JA, Wilhelm D, Sinclair AH \& Western PS 2013 Signaling through the TGF beta-activin receptors ALK4/5/7 regulates testis formation and male germ cell development. PLOS ONE 8 e54606. (https://doi.org/10.1371/journal. pone.0054606)

Mitchell RT, Cowan G, Morris KD, Anderson RA, Fraser HM, Mckenzie KJ, Wallace WHB, Kelnar CJH, Saunders PTK \& Sharpe RM 2008 Germ cell differentiation in the marmoset (Callithrix jacchus) during fetal and neonatal life closely parallels that in the human. Human Reproduction 23 2755-2765. (https://doi.org/10.1093/humrep/den295)
Mohammadi M, McMahon G, Sun L, Tang C, Hirth P, Yeh BK, Hubbard SR \& Schlessinger J 1997 Structures of the tyrosine kinase domain of fibroblast growth factor receptor in complex with inhibitors. Science $\mathbf{2 7 6}$ 955-960. (https://doi.org/10.1126/science.276.5314.955)

Molyneaux KA, Stallock J, Schaible K \& Wylie C 2001 Time-lapse analysis of living mouse germ cell migration. Developmental Biology 240 488-498. (https://doi.org/10.1006/dbio.2001.0436)

Nettersheim D, Jostes S, Sharma R, Schneider S, Hofmann A, Ferreira HJ, Hoffmann P, Kristiansen G, Esteller MB \& Schorle H 2015 BMP inhibition in seminomas initiates acquisition of pluripotency via NODAL signaling resulting in reprogramming to an embryonal carcinoma. PLoS Genetics 11 1-26. (https://doi.org/10.1371/journal.pgen.1005415)

Ostrer H, Huang HY, Masch RJ \& Shapiro E 2007 A cellular study of human testis development. Sexual Development 1 286-292. (https://doi. org/10.1159/000108930)

Papanayotou C \& Collignon J 2014 Activin/Nodal signalling before implantation: setting the stage for embryo patterning. Philosophical Transactions of the Royal Society of London: Series B, Biological Sciences 369 20130539. (https://doi.org/10.1098/rstb.2013.0539)

Pauls K, Schorle H, Jeske W, Brehm R, Steger K, Wernert N, Büttner R \& Zhou H 2006 Spatial expression of germ cell markers during maturation of human fetal male gonads: an immunohistochemical study. Human Reproduction 21 397-404. (https://doi.org/10.1093/humrep/dei325)

Rajpert-De Meyts E 2006 Developmental model for the pathogenesis of testicular carcinoma in situ: genetic and environmental aspects. Human Reproduction Update 12 303-323. (https://doi.org/10.1093/humupd/ dmk006)

Rajpert-De Meyts E, Hanstein R, Jørgensen N, Graem N, Vogt PH \& Skakkebaek NE 2004 Developmental expression of POU5F1 (OCT-3/4) in normal and dysgenetic human gonads. Human Reproduction 19 1338-1344. (https://doi.org/10.1093/humrep/deh265)

Rajpert-De Meyts E, McGlynn KA, Okamoto K, Jewett MAS \& Bokemeyer C 2016 Testicular germ cell tumours. Lancet 387 1762-1774. (https://doi. org/10.1016/S0140-6736(15)00991-5)

Rotgers E, Jørgensen A \& Yao HH 2018 At the crossroads of fate - somatic cell lineage specification in the fetal gonad. Endocrine Reviews 39 739-759. (https://doi.org/10.1210/er.2018-00010)

Sakuma R, Ohnishi YI, Meno C, Fujii H, Juan H, Takeuchi J, Ogura T, Li E, Miyazono K \& Hamada H 2002 Inhibition of Nodal signalling by Lefty mediated through interaction with common receptors and efficient diffusion. Genes to Cells 7 401-412. (https://doi.org/10.1046/j.13652443.2002.00528.x)

Schier AF 2009 Nodal morphogens. Cold Spring Harbor Perspectives in Biology 1 a003459. (https://doi.org/10.1101/cshperspect.a003459)

Sharpe RM 2006 Pathways of endocrine disruption during male sexual differentiation and masculinisation. Best Practice and Research: Clinical Endocrinology and Metabolism 20 91-110. (https://doi.org/10.1016/j. beem.2005.09.005)

Sinclair AH, Berta P, Palmer MS, Hawkins JR, Griffiths BL, Smith MJ, Foster JW, Frischauf AM, Lovell-Badge R \& Goodfellow PN 1990 A gene from the human sex-determining region encodes a protein with homology to a conserved DNA-binding motif. Nature 346 240-244. (https://doi.org/10.1038/346240a0)

Skakkebaek NE, Berthelsen JG, Giwercman A \& Müller J 1987 Carcinomain-situ of the testis: possible origin from gonocytes and precursor of all types of germ cell tumours except spermatocytoma. International Journal of Andrology 10 19-28. (https://doi.org/10.1111/j.1365-2605.1987. tb00161.x)

Skakkebaek NE, Rajpert-De Meyts E \& Main KM 2001 Testicular dysgenesis syndrome: an increasingly common developmental disorder with environmental aspects. Human Reproduction 16 972-978. (https://doi. org/10.1093/humrep/16.5.972)

Skakkebaek NE, Rajpert-De Meyts E, Buck Louis GM, Toppari J, Andersson AM, Eisenberg ML, Jensen TK, Jørgensen N, Swan SH, Sapra KJ et al. 2016 Male reproductive disorders and fertility trends: influences of environment and genetic susceptibility. Physiological Reviews 96 55-97. (https://doi.org/10.1152/ physrev.00017.2015)

Souquet B, Tourpin S, Messiaen S, Moison D, Habert R \& Livera G 2012 Nodal signaling regulates the entry into meiosis in fetal germ cells. Endocrinology 153 2466-2473. (https://doi.org/10.1210/en.20112056) 
Spiller CM, Feng CW, Jackson A, Gillis AJ, Rolland AD, Looijenga LH, Koopman P \& Bowles J 2012 Endogenous Nodal signaling regulates germ cell potency during mammalian testis development. Development 139 4123-4132. (https://doi.org/10.1242/dev.083006)

Spiller CM, Bowles J \& Koopman P 2013 Nodal/cripto signaling in fetal male germ cell development: implications for testicular germ cell tumors. International Journal of Developmental Biology 57 211-219. (https://doi.org/10.1387/ijdb.130028pk)

Spiller C, Burnet G \& Bowles J 2017 Regulation of fetal male germ cell development by members of the TGF $\beta$ superfamily. Stem Cell Research 24 174-180. (https://doi.org/10.1016/j.scr.2017.07.016)

Stoop H, Honecker F, Cools M, de Krijger R, Bokemeyer C \& Looijenga LHJ 2005 Differentiation and development of human female germ cells during prenatal gonadogenesis: an immunohistochemical study. Human Reproduction 20 1466-1476. (https://doi.org/10.1093/humrep/deh800)

Suzuki A \& Saga Y 2008 Nanos2 suppresses meiosis and promotes male germ cell differentiation. Genes and Development 22 430-435. (https:// doi.org/10.1101/gad.1612708)

Tian-Zhong M, Bi C, Ying Z, Xia J, Cai-Ling P, Yun-Shan Z, Mei-Wen H \& Yan-Ru N 2016 Critical role of emx2 in the pluripotency - differentiation transition in male gonocytes via regulation of FGF9/nodal pathway. Reproduction 151 673-681. (https://doi.org/10.1530/REP-16-0022)

Vallier L, Reynolds D \& Pedersen RA 2004 Nodal inhibits differentiation of human embryonic stem cells along the neuroectodermal default pathway.
Developmental Biology 275 403-421. (https://doi.org/10.1016/j. ydbio.2004.08.031)

Welsh M, Saunders PTK, Fisken M, Scott HM, Hutchison GR, Smith LB \& Sharpe RM 2008 Identification in rats of a programming window for reproductive tract masculinization, disruption of which leads to hypospadias and cryptorchidism. Journal of Clinical Investigation 118 1479-1490. (https://doi.org/10.1172/JCI34241)

Wilhelm D, Yang JX \& Thomas P 2013 Mammalian sex determination and gonad development. In Current Topics in Developmental Biology, 1st ed, vol. 106, pp 89-121. Elsevier Inc. (https://doi.org/10.1016/B978-012-416021-7.00003-1)

Wu Q, Kanata K, Saba R, Deng CX, Hamada H \& Saga Y 2013 Nodal/ activin signaling promotes male germ cell fate and suppresses female programming in somatic cells. Development 140 291-300. (https://doi. org/10.1242/dev.087882)

Received 20 December 2018

First decision 18 February 2019

Revised manuscript received 26 February 2019

Accepted 18 April 2019 